\title{
Functional (psychogenic) movement disorders
}

\author{
Kathrin Czarnecki and Mark Hallett \\ Human Motor Control Section, NINDS, NIH, Bethesda, MD, USA
}

\begin{abstract}
Purpose of review-This review provides an overview of recent developments in diagnosis, pathophysiology, neuroimaging and management of functional (psychogenic) movement disorders (FMD) and highlights the current controversy on classification of somatoform disorders in the new DSM-5.
\end{abstract}

Recent findings-There has been increasing interest in recent years to study the underlying pathophysiology of FMDs, which has resulted in a broadened disease model, taking neurobiologic and psychosocial factors equally into account. In this context, the term "psychogenic" has been replaced by "functional" movement disorders by many authors in the field to express the changing focus towards a multifactorial disease model.

The need for establishing a positive diagnosis of FMD as opposed to providing a diagnosis of exclusion is increasingly recognized and reflected by the introduction of "laboratory-supported" diagnostic criteria of FMD. Important advances have been made through behavioral, electrophysiological and neuroimaging studies although the fundamental etiology of FMD remains poorly understood. Of particular interest have been several reports on abnormal sensorimotor features and cortical inhibition in both organic and functional dystonia, highlighting possible shared traits of both conditions. In terms of treatment, recent studies have reported benefit from both psychiatric and physical therapy based interventions.

Summary-Increasing efforts have been made towards better understanding and treatment of FMD, and the disease model has been broadened to include neurobiologic and psychosocial factors. Laboratory-based diagnostic criteria have been established for many FMDs to support the clinical diagnosis. To determine the most effective management strategies for FMD, a closer collaboration between neurologists and psychiatrists and intensified research efforts with prospective treatment trials are needed.

\section{Keywords}

Psychogenic movement disorders; conversion; hysteria; neurophysiology

\section{Introduction and Classification}

Patients with FMD present a challenge to neurologists and psychiatrists alike, as the underlying nature of the disorder remains poorly understood. It is increasingly recognized

Corresponding author: Mark Hallett, M.D., Chief, Human Motor Control Section, NINDS, NIH, Bldg. 10, rm. 7D37, 10 Center Dr. MSC 1428, Bethesda, MD 20892-1428, Tel: 301-496-9526, Fax: 301-480-2286, hallettm@ninds.nih.gov. 
that psychological factors alone are not sufficient to explain their etiology and other elements such as genetic susceptibility and neurobiological factors are implicated. The most commonly used terms in the neurologic literature, "psychogenic" and "conversion", carry many negative connotations with patients and clinical providers and convey the notion of a uniformly psychological etiology of the disorder. Several authors now prefer the term "functional" movement disorders which seems to be better suited to encompass a wider, biopsychosocial disease model [1] [2] and is also used by other medical specialties for nonorganic disorders (e.g., functional gastrointestinal disorders).

The lack of a common terminology is also evident when comparing diagnostic criteria between neurologists and psychiatrists [3]. The current classification in the Diagnostic and Statistical Manual of Mental Disorders (DSM-IV-TR) for somatoform disorders distinguishes between conversion disorder (applicable to most FMD patients), somatization disorder and undifferentiated somatoform disorder, although the classification for the new DSM-V is actively debated [4], [5].

The notion of underlying emotional or sexual trauma converted into a motor manifestation is still a popular, yet ultimately unproven theory tracing its roots back to Charcot and Freud. A review of the history of hysteria points out Charcot's lasting influence on current theories [6]. While a recent study confirmed higher rates of childhood trauma in FMD patients compared to healthy volunteers [7], psychopathology is not always evident. Of note, a history of abuse is less frequent compared to patients with psychogenic non-epileptic seizures despite many other shared features between these patient populations [7], [8].

\section{Updates on clinical features}

Several recent studies describe distinct findings on clinical examination that can be helpful in the diagnosis of FMD. Fekete et al. [9] draw attention to the frequent presence of convergence spasm, characterized as transient ocular convergence, miosis and accommodation with disconjugate gaze mimicking abducens palsy. While this finding can be an indicator of brainstem pathology, it was found in $69 \%$ of patients with conversion disorder. Although the study is limited by a small sample size, the recognition of an association between convergence spasm and psychogenic disease may avoid unnecessary investigations.

Espay and Lang report on differentiating features of toe signs between psychogenic and organic disease [10]. While baseline posturing with extension of the first toe and flexion of toes 2-5 can be seen in organic and psychogenic conditions, pain and variable resistance during toe movements and plantar flexion of the first toe during forced dorsiflexion of toes 2-5 are psychogenic signs.

In accordance with a theory of sensory misperception or failure to correctly integrate sensory information in FMD, Stone et al. [11] report abnormal perception of ankle position in psychogenic dystonia. Patients with both fixed and variable psychogenic foot dystonia inaccurately reported their ankle to be in a "straight" position when visual input was eliminated. Some patients with fixed functional dystonia experience great psychological distress by their symptoms and may seek amputation of the affected limb [12]. 
Based on the well-established finding of distractibility, van Poppelen et al. [13] hypothesized that FMD patients may show increased attentional focus towards their affected body parts while experiencing abnormal movements. Their study of psychogenic and organic tremor patients provided ratings of visual attention towards trembling extremities during videotaped, standardized tasks for tremor assessment. Patients with psychogenic tremor showed about twice as much visual attention towards tremor-affected limbs compared to organic tremor patients $(66 \%$ versus $32 \%, \mathrm{p}=0.001)$. Taken in conjunction with other features on clinical examination, increased visual attention to affected body parts may be a useful supportive feature in FMD.

\section{Updates on diagnosis}

The diagnosis of FMD is based on clinical criteria such as inconsistency of movements over time, incongruence with typical features of movement disorders or persistent relief by psychotherapy, suggestion or placebo. It is important to note that symptoms are perceived as involuntary by the patient which is a discriminating feature from factitious disorders and malingering, where patients present with voluntarily produced symptoms for primary or secondary gain. (Of course, in these two situations, the patients do not admit that the movements are voluntary.) The most commonly used criteria by Fahn and Williams distinguish between clinically documented, clinically established, probable and possible FMD [14], [15]. Gupta and Lang proposed revised criteria in 2009 with the introduction of a "laboratory supported, definite" diagnostic category based on electrophysiologic testing [16]. These criteria reflect increasing efforts to support a diagnosis of FMD with supplementary physiological testing, such as tremor analysis for functional tremor and EMG-EEG backaveraging for functional myoclonus [17], [18].

Schwingenschuh et al. [19] reported on the specificity and sensitivity of several electrophysiological tests to distinguish psychogenic from organic tremor. They propose a combination of tests including tapping task performance at different frequencies, entrainment, and pause or amplitude shift with ballistic movements to reach a "laboratorysupported" diagnostic level of psychogenic tremor. Given the limited availability of formal electrophysiologic tremor assessments in clinical practice, it is important to note that several of these tests can also be informative when performed during the neurologic examination [20]. In cases where Parkinson's disease is a possible differential diagnosis, dopamine transporter (DaT)-imaging has been shown to be a useful test to distinguish neurodegenerative Parkinsonism from conditions without a presynaptic dopaminergic deficit, such as psychogenic Parkinsonism [21], [22].

\section{Updates on neuropsychology}

Parees et al. [23] report a significant mismatch between self-report of tremor and actual tremor measurements by actigraphy over an extended period of time. In their study, patients with psychogenic tremor overestimated tremor by $65 \%$ compared to actigraphy recordings, while patients with organic tremor reported only $28 \%$ more than actigraphy. The failure to accurately report absence of tremor during most of the day in PMD patients may suggest an 
abnormal overweighting of prior tremor expectations leading to a distortion in sensory perception.

Edwards et al [24] studied the sense of intention for volitional movements in functional tremor patients with a Libet clock experiment [25] and found a significantly shorter interval between reported intention to move and an actual performed movement compared to a control group. The findings suggest an impaired sense of volition which could interfere with the conscious experience of voluntary movements in FMD patients.

\section{Updates on pathophysiology}

Schwingenschuh et al. [26] demonstrated a normal blink reflex recovery cycle in nine patients with psychogenic blepharospasm, whereas patients with essential blepharospasm show significant disinhibition of the reflex recovery cycle, reflecting enhanced brainstem excitability. If confirmed in a larger patient population, this test may be a valuable diagnostic tool in distinguishing essential from psychogenic blepharospasm.

Kobayashi et al. [27] reported on thalamic neuronal activity in a patient who underwent thalamotomy for suspected primary dystonia before the correct diagnosis of FMD was made. Interestingly, the neuronal firing rate in the ventral oral posterior nucleus of the thalamus and thalamic reorganization were found to be comparable to 9 patients with organic dystonia, suggesting shared electrophysiological patterns. These findings are of particular interest as several previous studies have reported similar abnormalities in inhibitory cortical circuits in both primary and psychogenic dystonia, using transcranial magnetic stimulation (TMS) as an experimental method [28], [29]. Two features were different in the FMD patient, the EMG coherence between involved muscles and the signal-to-noise ratio in thalamic neuronal recordings (both higher in organic dystonia). The former is a non-invasive observation and should be further pursued.

Morgante et al [30] provide evidence for abnormal sensorimotor processing with higher temporal discrimination thresholds for tactile stimuli in psychogenic and primary torsion dystonia patients. Abnormal findings were demonstrated in both affected and non-affected limbs and persisted on follow-up after 12 months. In contrast to these studies, measurements of cortical plasticity revealed an abnormally high response to paired associative stimuli (PAS) in organic, but not psychogenic dystonia [31]. This latter finding is important, since it is the only electrophysiological test so far reported that will differentiate organic and functional dystonia.

In summary, it has become clear that certain neurophysiological featues including temporal discrimination thresholds and intracortical inhibition are similarly affected in organic and psychogenic dystonia. These findings suggest a common vulnerability for the development of dystonic postures, while abnormal cortical plasticity appears to be a distinguishing feature of organic dystonia. 


\section{Updates on neuroimaging}

Previous work of Voon et al. [32] has demonstrated impaired habituation to arousing stimuli and greater functional connectivity between amygdala and supplementary motor area in FMD patients. Extending on these findings, a recent fMRI study revealed greater activity in limbic structures (right amygdala, left anterior insula and bilateral posterior cingulate area) and decreased activity in the left supplementary motor area (SMA) during a motor preparation task in FMD patients compared to controls [33]. The findings of lower activity in regions associated with motor preparation and greater activity in limbic structures during motor preparation reveal a possible mechanism of abnormal emotional processing interfering with normal motor planning. In addition, the left SMA had lower functional connectivity with bilateral dorsolateral prefrontal cortex regions during internally versus externally generated movements, providing evidence for impaired top-down regulation of action selection.

Patients with fixed dystonia (who are thought to have mostly FMD) have been found to exhibit difficulties with mental rotation of body parts [34], a finding previously demonstrated in cervical dystonia patients [35]. These studies support the above mentioned hypothesis of a shared predisposition for dystonic postures in organic and functional dystonia based on electrophysiologic findings. Patients with fixed dystonia may share features with a right parietal lobe syndrome termed "xenomelia" [36], describing otherwise healthy individuals seeking limb amputations. In an MEG study of four patients with this syndrome, reduced activation was found in the right superior parietal lobule during sensory stimulation of the affected limb [36], a brain region associated with body image and out-ofbody experience [37].

\section{Updates on post-traumatic dystonia}

The entity of post-traumatic dystonia and its overlap with complex regional pain syndrome (CRPS) dystonia remains a controversial topic. It was previously reported that peripheral nerve injury may trigger a variety of movement disorders, most commonly dystonia, in susceptible individuals [38] potentially due to neuroplastic changes related to pain and altered sensory input [39]. In a recent review of the literature on 713 patients with peripherally induced movement disorders [40], the authors find overlap with FMD in 15\% of cases, but argue for presence of an organic movement disorder triggered by peripheral trauma in the majority of cases. An opposing view is taken by Hawley and Weiner [41], who make a case for a predominant psychogenic etiology in patients peripheral trauma associated dystonia. The use of electrophysiological methods such as measurements of cortical plasticity in this patient population [42] will hopefully provide a more definitive answer on the underlying pathophysiology in these cases.

\section{Updates on prognosis and treatment}

By definition, FMD symptoms are not based on irreversible structural neurological abnormalities and patients have the potential for a complete recovery. However, long-term follow-up studies have shown a high percentage of FMD patients with persistence of pathologic movements and development of additional unexplained medical symptoms [43]. 
Chronic disability in FMD patients has been found to be comparable to patients with Parkinson's disease, with even greater distress in quality of life and mental health measures [44]. Long duration of symptoms, insidious symptom onset and psychiatric co-morbidity are regarded negative prognostic factors [43], while patient's perception of effective treatment by his physician and elimination of stressors are associated with improved outcome [45].

There are to date no official guidelines for the treatment of functional movement disorders and there continues to be a lack of prospective, randomized treatment trials. Recent surveys among neurologists in the United States [46] and the UK [47] confirm the lack of uniform approach in managing FMD patients.

Current expert opinion stresses the importance of establishing a good rapport with the patient, communicating the diagnosis in clear terms [48], providing a disease model that allows patients to understand their symptoms, for example, by explaining typical functional features of the physical examination [2], and working in a multidisiplinary team with other health care providers [49].

In general, pharmacological therapy with drugs used for organic movement disorders should be avoided, but patients can benefit from treatment of psychiatric comorbidities such as anxiety and depression. A small study provided preliminary evidence for a positive effect of antidepressant treatment on motor conversion disorder [50]. Cognitive behavioral therapy (CBT) has been demonstrated to be more effective than standard medical care in patients with psychogenic non-epileptic seizures [51], [52] and is often recommended for FMD, especially if psychological stress factors can be identified [53].

Sharpe et al [54] demonstrated in a community-based study of functional neurological symptoms that patients can benefit from a CBT-based self-help manual with limited additional guidance and support.

The use of a physical therapy based treatment approach was examined retrospectively in 60 FMD patients and provided major self-reported symptom improvement which was maintained in over $60 \%$ of patients on a two year follow-up compared to $22 \%$ patients with improved symptoms in the control group [55]. Dallochhio et al. found positive effects on FMD from a general increase in physical activity by a walking program [56]. Other recent studies report benefit from the use of TENS [57] and transcranial magnetic stimulation (TMS) [58], but the lack of a control group in both studies and the known high placebo response in FMD patients have to be taken into account in interpreting the findings.

\section{Conclusion}

The increasing interest and recent advances in determining the pathophysiology of FMD is encouraging and has led to better recognition and improved diagnostic tests for these disorders. The need for improved collaboration between neurologists and psychiatrists in studying and treating FMD is recognized. While preliminary benefit has been reported from CBT and physical therapy based interventions, a pressing need remains for prospective interventional studies. 


\section{Acknowledgments}

This work was supported by the NINDS Intramural Program.

\section{References}

Papers of particular interest, published within the annual period of review, have been highlighted as:

- of special interest

•• of outstanding interest

1. Stone J, Edwards MJ. How "psychogenic" are psychogenic movement disorders? Movement Disorders. 2011; 26:1787-1788. [PubMed: 21761457]

2. Edwards MJ, Bhatia KP. Functional (psychogenic) movement disorders: merging mind and brain. Lancet Neurol. 2012; 11:250-260. [PubMed: 22341033]

3. Kranick SM, Gorrindo T, Hallett M. Psychogenic movement disorders and motor conversion: a roadmap for collaboration between neurology and psychiatry. Psychosomatics. 2011; 52:109-116. [PubMed: 21397102]

4. Nicholson TRJ, Stone J, Kanaan RAA. Conversion disorder: a problematic diagnosis. Journal of Neurology, Neurosurgery \& Psychiatry. 2010; 82:1267-1273.

5. Stone J, Lafrance WC Jr, Brown R, Spiegel D, Levenson JL, Sharpe M. Conversion disorder: current problems and potential solutions for DSM-5. J Psychosom Res. 2011; 71:369-376. [PubMed: 22118377]

6. Bogousslavsky J. Hysteria after Charcot: back to the future. Front Neurol Neurosci. 2011; 29:137161. [PubMed: 20938153]

7•. Kranick S, Ekanayake V, Martinez V, Ameli R, Hallett M, Voon V. Psychopathology and psychogenic movement disorders Movement Disorders. 2011; 26:1844-1850. Detailed neuropsychological assessment of 64 patients with FMD compared to focal dystonia and normal controls showed higher rates of childhood trauma in FMD, but no differences in many other psychological measures, stressing the importance of a disease model not exclusively focused on psychological factors. [PubMed: 21714007]

8. Driver-Dunckley E, Stonnington CM, Locke DE, Noe K. Comparison of psychogenic movement disorders and psychogenic nonepileptic seizures: is phenotype clinically important?

Psychosomatics. 2011; 52:337-345. [PubMed: 21777716]

9•. Fekete R, Baizabal-Carvallo JF, Ha AD, Davidson A, Jankovic J. Convergence spasm in conversion disorders: prevalence in psychogenic and other movement disorders compared with controls. Journal of Neurology, Neurosurgery \&. Psychiatry. 2011; 83:202-204. This casecontrol study finds a high prevalence of convergence spasm in FMD patients (9/13) presenting without eye related complaints. It is important to know that convergence spasm is not always a sign of brainstem pathology and indeed frequently present in FMD.

10•. Espay AJ, Lang AE. The psychogenic toe signs Neurology. 2011; 77:508-509. A patient with functional leg weakness, tremor and extension of the big toe is reported, highlighting differences in organic and psychogenic toe signs. [PubMed: 21810700]

11. Stone J, Gelauff J, Carson A. A "twist in the tale": Altered perception of ankle position in psychogenic dystonia. Mov Disord. 2011

12•. Edwards MJ, Alonso-Canovas A, Schrag A, Bloem BR, Thompson PD, Bhatia K. Limb amputations in fixed dystonia: a form of body integrity identity disorder? Mov Disord. 2011; 26:1410-1414. A report of 5 patients seeking amputation for fixed limb dystonia and pain, raising awareness for this highly disabling condition and proposing an underlying deficit in body integrity identity. [PubMed: 21484872]

13. van Poppelen D, Saifee TA, Schwingenschuh P, Katschnig P, Bhatia KP, Tijssen MA, Edwards MJ. Attention to self in psychogenic tremor. Mov Disord. 2011; 26:2575-2576. [PubMed: 22025317] 
14. Fahn S, Williams DT. Psychogenic dystonia. Adv Neurol. 1988; 50:431-455. [PubMed: 3400501]

15. Williams DT, Ford B, Fahn S. Phenomenology and psychopathology related to psychogenic movement disorders. Adv Neurol. 1995; 65:231-257. [PubMed: 7872143]

16. Gupta A, Lang AE. Psychogenic movement disorders. Curr Opin Neurol. 2009; 22:430-436. [PubMed: 19542886]

17. Bhatia KP, Schneider SA. Psychogenic tremor and related disorders. J Neurol. 2007; 254:569-574. [PubMed: 17417745]

18. Hallett M. Physiology of psychogenic movement disorders. J Clin Neurosci. 2010; 17:959-965. [PubMed: 20493708]

19•. Schwingenschuh P, Katschnig P, Seiler S, Saifee TA, Aguirregomozcorta M, Cordivari C, Schmidt R, Rothwell JC, Bhatia KP, Edwards MJ. Moving toward "laboratory- supported" criteria for psychogenic tremor Movement Disorders. 2011; 26:2509-2515. The study demonstrates that a combination of previously described electrophysiological tests shows good sensitivity and specificity in distinguishing psychogenic from organic tremor and may form the basis of a laboratory-supported diagnosis of functional tremor. [PubMed: 21956485]

20. Kenney C, Diamond A, Mejia N, Davidson A, Hunter C, Jankovic J. Distinguishing psychogenic and essential tremor. J Neurol Sci. 2007; 263:94-99. [PubMed: 17604055]

21. Gaig C, Marti MJ, Tolosa E, Valldeoriola F, Paredes P, Lomena FJ, Nakamae F. 123I-Ioflupane SPECT in the diagnosis of suspected psychogenic Parkinsonism. Mov Disord. 2006; 21:19941998. [PubMed: 16941463]

22. Kagi G, Bhatia KP, Tolosa E. The role of DAT-SPECT in movement disorders. J Neurol Neurosurg Psychiatry. 2010; 81:5-12. [PubMed: 20019219]

23••. Parees I, Saifee TA, Kassavetis P, Kojovic M, Rubio-Agusti I, Rothwell JC, Bhatia KP, Edwards MJ. Believing is perceiving: mismatch between self-report and actigraphy in psychogenic tremor. Brain. 2011 The study provides objective tremor recordings in 8 patients with functional tremor and organic tremor over 5 days. FMD patients show a significant mismatch between self-reported tremor compared to actigraphy data ( $4 \%$ versus $84 \%$ of the waking day), which may result from abnormal somatosensory perception and prediction errors.

24. Edwards MJ, Moretto G, Schwingenschuh P, Katschnig P, Bhatia KP, Haggard P. Abnormal sense of intention preceding voluntary movement in patients with psychogenic tremor. Neuropsychologia. 2011; 49:2791-2793. [PubMed: 21683724]

25. Libet B, Gleason CA, Wright EW, Pearl DK. Time of conscious intention to act in relation to onset of cerebral activity (readiness-potential). The unconscious initiation of a freely voluntary act. Brain. 1983; 106(Pt 3):623-642. [PubMed: 6640273]

26•. Schwingenschuh P, Katschnig P, Edwards MJ, Teo JT, Korlipara LV, Rothwell JC, Bhatia KP. The blink reflex recovery cycle differs between essential and presumed psychogenic blepharospasm Neurology. 2011; 76:610-614. A normal blink reflex recovery cycle was demonstrated in 9 patients with psychogenic blepharospasm, which may be a helpful diagnostic test for this condition with good differentiation from essential blepharospasm. [PubMed: 21321334]

27••. Kobayashi K, Lang AE, Hallett M, Lenz FA. Thalamic neuronal and EMG activity in psychogenic dystonia compared with organic dystonia Mov Disord. 2011; 26:1348-1352. Electrophysiologic data obtained during thalamotomy from a patient with initially misdiagnosed psychogenic dystonia is presented. While several features are different from a control group of organic dystonia patients, there are similarities in thalamic firing rates and reorganization, suggesting shared electrophysiological features in both conditions; either predisposing to or resulting from dystonic postures. [PubMed: 21500279]

28. Espay AJ, Morgante F, Purzner J, Gunraj CA, Lang AE, Chen R. Cortical and spinal abnormalities in psychogenic dystonia. Ann Neurol. 2006; 59:825-834. [PubMed: 16634038]

29. Avanzino L, Martino D, van de Warrenburg BP, Schneider SA, Abbruzzese G, Defazio G, Schrag A, Bhatia KP, Rothwell JC. Cortical excitability is abnormal in patients with the "fixed dystonia" syndrome. Mov Disord. 2008; 23:646-652. [PubMed: 18175341]

30• Morgante F, Tinazzi M, Squintani G, Martino D, Defazio G, Romito L, Albanese A, Di Matteo A, Quartarone A, Girlanda P, et al. Abnormal tactile temporal discrimination in psychogenic 
dystonia Neurology. 2011; 77:1191-1197. This study demonstrates abnormal processing of somatosensory input in primary torsion dystonia as well as psychogenic dystonia, suggesting possible common neurophysiologic traits predisposing to development of dystonic postures in both conditions. [PubMed: 21900627]

31. Quartarone A, Rizzo V, Terranova C, Morgante F, Schneider S, Ibrahim N, Girlanda P, Bhatia KP, Rothwell JC. Abnormal sensorimotor plasticity in organic but not in psychogenic dystonia. Brain. 2009; 132:2871-2877. [PubMed: 19690095]

32. Voon V, Brezing C, Gallea C, Ameli R, Roelofs K, LaFrance WC Jr, Hallett M. Emotional stimuli and motor conversion disorder. Brain. 2010; 133:1526-1536. [PubMed: 20371508]

33•. Voon V, Brezing C, Gallea C, Hallett M. Aberrant supplementary motor complex and limbic activity during motor preparation in motor conversion disorder Movement Disorders. 2011; 26:2396-2403. This fMRI study with 16 FMD patients reveals greater functional connectivity between the right amygdala and supplementary motor cortex during presentation with emotional stimuli, providing a potential model how emotional triggers may exacerbate motor symptoms. [PubMed: 21935985]

34. Katschnig P, Edwards MJ, Schwingenschuh P, Aguirregomozcorta M, Kagi G, Rothwell JC, Bhatia KP. Mental rotation of body parts and sensory temporal discrimination in fixed dystonia. Mov Disord. 2010; 25:1061-1067. [PubMed: 20310052]

35. Fiorio M, Tinazzi M, Ionta S, Fiaschi A, Moretto G, Edwards MJ, Bhatia KP, Aglioti SM. Mental rotation of body parts and non-corporeal objects in patients with idiopathic cervical dystonia. Neuropsychologia. 2007; 45:2346-2354. [PubMed: 17412373]

36. McGeoch PD, Brang D, Song T, Lee RR, Huang M, Ramachandran VS. Xenomelia: a new right parietal lobe syndrome. J Neurol Neurosurg Psychiatry. 2011; 82:1314-1319. [PubMed: 21693632]

37. De Ridder D, Van Laere K, Dupont P, Menovsky T, Van de Heyning P. Visualizing out-of-body experience in the brain. N Engl J Med. 2007; 357:1829-1833. [PubMed: 17978291]

38. Jankovic J, Van der Linden C. Dystonia and tremor induced by peripheral trauma: predisposing factors. J Neurol Neurosurg Psychiatry. 1988; 51:1512-1519. [PubMed: 3221219]

39. Navarro X, Vivo M, Valero-Cabre A. Neural plasticity after peripheral nerve injury and regeneration. Prog Neurobiol. 2007; 82:163-201. [PubMed: 17643733]

40. van Rooijen DE, Geraedts EJ, Marinus J, Jankovic J, van Hilten JJ. Peripheral trauma and movement disorders: a systematic review of reported cases. Journal of Neurology, Neurosurgery \& Psychiatry. 2011; 82:892-898.

41. Hawley JS, Weiner WJ. Psychogenic dystonia and peripheral trauma. Neurology. 2011; 77:496502. [PubMed: 21810699]

42. Quartarone A, Pisani A. Abnormal plasticity in dystonia: Disruption of synaptic homeostasis. Neurobiol Dis. 2011; 42:162-170. [PubMed: 21168494]

43. Feinstein A, Stergiopoulos V, Fine J, Lang AE. Psychiatric outcome in patients with a psychogenic movement disorder: a prospective study. Neuropsychiatry Neuropsychol Behav Neurol. 2001; 14:169-176. [PubMed: 11513100]

44. Anderson KE, Gruber-Baldini AL, Vaughan CG, Reich SG, Fishman PS, Weiner WJ, Shulman LM. Impact of psychogenic movement disorders versus Parkinson's on disability, quality of life, and psychopathology. Mov Disord. 2007; 22:2204-2209. [PubMed: 17876850]

45. Thomas M, Vuong KD, Jankovic J. Long-term prognosis of patients with psychogenic movement disorders. Parkinsonism Relat Disord. 2006; 12:382-387. [PubMed: 16737838]

46. Espay AJ, Goldenhar LM, Voon V, Schrag A, Burton N, Lang AE. Opinions and clinical practices related to diagnosing and managing patients with psychogenic movement disorders: An international survey of movement disorder society members. Mov Disord. 2009; 24:1366-1374. [PubMed: 19425106]

47. Kanaan RA, Armstrong D, Wessely SC. Neurologists' understanding and management of conversion disorder. J Neurol Neurosurg Psychiatry. 2011; 82:961-966. [PubMed: 21325661]

48. Friedman JH, LaFrance WC Jr. Psychogenic disorders: the need to speak plainly. Arch Neurol. 2010; 67:753-755. [PubMed: 20558396] 
49. Williams DT, Ford B, Fahn S. Treatment issues in psychogenic-neuropsychiatric movement disorders. Adv Neurol. 2005; 96:350-363. [PubMed: 16383231]

50. Voon V, Lang AE. Antidepressant treatment outcomes of psychogenic movement disorder. J Clin Psychiatry. 2005; 66:1529-1534. [PubMed: 16401153]

51. LaFrance WC Jr, Miller IW, Ryan CE, Blum AS, Solomon DA, Kelley JE, Keitner GI. Cognitive behavioral therapy for psychogenic nonepileptic seizures. Epilepsy Behav. 2009; 14:591-596. [PubMed: 19233313]

52. Goldstein LH, Chalder T, Chigwedere C, Khondoker MR, Moriarty J, Toone BK, Mellers JD. Cognitive-behavioral therapy for psychogenic nonepileptic seizures: a pilot RCT. Neurology. 2010; 74:1986-1994. [PubMed: 20548043]

53. LaFrance WC Jr, Friedman JH. Cognitive behavioral therapy for psychogenic movement disorder. Mov Disord. 2009; 24:1856-1857. [PubMed: 19562779]

54- Sharpe M, Walker J, Williams C, Stone J, Cavanagh J, Murray G, Butcher I, Duncan R, Smith S, Carson A. Guided self-help for functional (psychogenic) symptoms. a randomized controlled efficacy trial Neurology. 2011; 77:564-572. This trial of 127 patients with functional neurological symptoms (including movement disorders) provides class III evidence for greater improvement of general health with use of a CBT-based manual over standard medical care. [PubMed: 21795652]

55•. Czarnecki K, Thompson JM, Seime R, Geda YE, Duffy JR, Ahlskog JE. Parkinsonism Relat Disord. 2011 Functional movement disorders: Successful treatment with a physical therapy rehabilitation protocol. A retrospective case-control series of 60 FMD patients, with self-reported marked symptom improvement in $60 \%$ (compared to $22 \%$ of controls) two years after a physical therapy oriented rehabilitation program.

56. Dallocchio C, Arbasino C, Klersy C, Marchioni E. The effects of physical activity on psychogenic movement disorders. Mov Disord. 2010; 25:421-425. [PubMed: 20108357]

57. Ferrara J, Stamey W, Strutt AM, Adam OR, Jankovic J. Transcutaneous electrical stimulation (TENS) for psychogenic movement disorders. J Neuropsychiatry Clin Neurosci. 2011; 23:141148. [PubMed: 21677241]

58. Dafotakis M, Ameli M, Vitinius F, Weber R, Albus C, Fink GR, Nowak DA. [Transcranial magnetic stimulation for psychogenic tremor - a pilot study]. Fortschr Neurol Psychiatr. 2011; 79:226-233. [PubMed: 21480152] 


\section{Key points}

- The underlying disease model has changed from a primarily psychological to a neurobiopsychosocial model, reflected by the preference of many physicians for the term "functional" rather than "psychogenic" movement disorders.

- Diagnosis is based on positive criteria by history and examination, and can be supported by electrophysiological tests for many movement categories, such as functional tremor and myoclonus.

- Several studies demonstrate shared electrophysiological features between functional and organic dystonia, making a common predisposition for development of dystonic postures likely.

- While advances in the treatment of FMD have been made, a closer collaboration between neurologists and psychiatrists and increased efforts to prospectively study therapeutic interventions is needed. 